\title{
Designing Learning Spaces for Interprofessional Education in the Anatomical Sciences
}

\author{
Benjamin Cleveland, ${ }^{*}$ Thomas Kvan \\ Learning Environments Applied Research Network (LEaRN), Melbourne School of Design, Faculty \\ of Architecture Building and Planning, University of Melbourne, Parkville, Victoria, Australia
}

\begin{abstract}
This article explores connections between interprofessional education (IPE) models and the design of learning spaces for undergraduate and graduate education in the anatomical sciences and other professional preparation. The authors argue that for IPE models to be successful and sustained they must be embodied in the environment in which interprofessional learning occurs. To elaborate these arguments, two exemplar tertiary education facilities are discussed: the Charles Perkins Centre at the University of Sydney for science education and research, and Victoria University's Interprofessional Clinic in Wyndham for undergraduate IPE in health care. Backed by well-conceived curriculum and pedagogical models, the architectures of these facilities embody the educational visions, methods, and practices they were designed to support. Subsequently, the article discusses the spatial implications of curriculum and pedagogical change in the teaching of the anatomical sciences and explores how architecture might further the development of IPE models in the field. In conclusion, it is argued that learning spaces should be designed and developed (socially) with the expressed intention of supporting collaborative IPE models in health education settings, including those in the anatomical sciences. Anat Sci Educ 8: 371380. ㄷ 2015 American Association of Anatomists.
\end{abstract}

Key words: anatomical sciences education; medical education; undergraduate education; educational methodology; interprofessional education; learning spaces; space design; architecture

\section{INTRODUCTION}

In 1910, the Flexner Report changed the face of medical education in the United States and Canada and has since influenced the way medical education has been structured around the world (Flexner, 1910; Cooke et al., 2006). Three key recommendations of the report included: (1) training physicians to practice in a scientific manner and engaging medical faculty in research, (2) giving medical schools control of clinical instruction in hospitals, and (3) bioscience should be taught in the university and clinical education in the hospital (Flexner, 1910). Embedded in the report was the assumption that

*Correspondence to: Dr. Benjamin Cleveland, Learning Environments Applied Research Network (LEaRN), Faculty of Architecture Building and Planning, University of Melbourne, Parkville, Victoria 3010, Australia. E-mail: benjamin.cleveland@unimelb.edu.au

Received 8 March 2015; Revised 1 April 2015; Accepted 14 April 2015.

Published online 7 May 2015 in Wiley Online Library (wileyonlinelibrary.com). DOI 10.1002/ase.1539 medical practitioners should be trained separately from other health professionals (Flexner, 1910).

A little over 100 years later, momentum is gathering behind a review of the way medical education is delivered and a new paradigm in medical education is emerging (Cooke et al., 2010; Bleakley et al., 2011; Dornan et al., 2011). In an article introducing a series on medical education reform in the United States, Cooke et al. (2006) asked, "What can be done to bring the knowledge, skills, and values that must be imparted by medical education into better balance and to prepare outstanding physicians for the 21st century?" These authors argued that change was required due to academic and clinical practice settings having transformed since Flexner (Cooke et al., 2006). Citing reports from task forces, boards, and education bodies over the past century, Cooke et al. (2010) also criticized the ongoing emphasis in medical education of scientific knowledge over clinical reasoning, practical skill, character development, and biologic understanding. Likewise, Louie et al. (2007) argued that making meaning was critical to medical students in the transition from being memorizers of facts to becoming reasoning practicing clinicians. They suggested that a sociocultural approach to training, including interprofessional education 
(IPE), encouraged teaching techniques that made the belief systems of the medical care community more transparent to trainees. Others have also recognized the importance of introducing IPE in the preclinical phase of medical education (Kirch and Ast, 2015; Thistlethwaite, 2015).

In accordance with growing interest in the value of IPE models in health care, this article discusses connections between IPE models and the design of learning spaces for undergraduate and graduate education in the anatomical sciences and other professional preparation. Specifically, the article debates how architecture might enhance the development of IPE models and explores the spatial implications of curriculum and pedagogical change in the teaching of the anatomical sciences.

The IPE is defined as the opportunity for "two or more professions to learn with, from and about each other in order to improve collaboration and the quality of care" (CAIPE, 2002; Freeth et al., 2005). Showing that many opportunities exist to engage trainees in IPE, Barr (1996) categorized five dominant IPE models: (1) exchange-based (sharing of views); (2) action-based (working collaboratively on a project); (3) observation-based (shadowing different professions followed by discussion); (4) simulation-based (role play and skills labs); and (5) practice-based (assigning two or more students from different professions to the same placement). With growing evidence of the benefits of interprofessional care models to health outcomes, the development of effective interprofessional training programs seems to be essential (McNair et al., 2005). Reviews of such programs have identified the following benefits: improved communication between professions, higher levels of respect between team members, better understanding of roles, enhanced collaborative skills, higher levels of patient-centeredness, and improved efficiency and cost-effectiveness of care (McNair et al., 2005).

Consistent with the push toward the interprofessional training of health professionals, Arky (2006) argued that although practices in wards and clinics have changed drastically over the past 50 years, "we persist in using the same old educational model." Arky (2006) also suggested that efforts to reform medical education since Flexner's report have been hampered by traditional boundaries among departments and argued that traditionalists have "disparaged efforts to integrate the pieces into an orderly whole." Admitting that medicine has not always appreciated the science of teaching as a specialty, Arky (2006) argued that it was time for a change, noting that although there have been innumerable clinical trials involving treatments in various specialties, similar trials of educational methods and the instruction of medical students are rare. Recognizing that people learn in different fashions and that effective teaching requires more than knowledge about subject matter, Arky (2006) suggested that "learning environments" that cater for students' motivations and experiences are needed and predicted that digital technology would streamline medical education, just as it has medical practice.

According to Reeves and Hean (2013), the range of collaborative and practice-based activities medical education encompasses, as well as the outcomes of such activities, have been more closely considered by those in the field in recent years. In a presentation titled, The Future of Medical Education given at the Talking Spaces 6 Symposium at the University of Melbourne in 2014, Head of the Melbourne Medical School imagined learning for medical students in the future comprising a blend of bioscience, population health, and clin- ical learning (McColl, 2014). He envisaged that virtual clinical cases would continue in the early part of medical degree courses and technology would enable bioscience and population health to be meaningfully integrated into the clinical years. McColl (2014) saw clinical learning as comprising the triad of patient, student, and teacher, and suggested that methods needed to be found to maximize this "collaboration" in all hospital and community environments; including inpatients, outpatients, and ambulatory care; inner and outer metropolitan areas and rural zones; and in simulations. He foresaw that medical students would be engaged in meaningful clinical tasks in all the above settings, actively working with other health professionals (McColl, 2014).

With respect to the anatomical sciences, a number of authors have identified the teaching of anatomy as a forum particularly well suited to IPE (Hamilton et al., 2008; Fernandes et al., 2015; Herrmann et al., 2015; Kirch and Ast, 2015; Thistlethwaite, 2015). Herrmann et al. (2015) described IPE that combines anatomy and nursing topics as "an optimal setting for learning together," whereas Kirch and Ast (2015) described anatomy education as playing a leading role in the development and adoption of IPE principles across a variety of professions and disciplines.

Although academic programs in medicine, nursing, and other health professions are increasingly expected to educate students in cross-disciplinary groups "to prepare them for effective teamwork and collaborative decision making in clinical practice" (Lamb and Shraiky, 2013), siloed training and regulation, differentiated power, competition for status and resources, and protection of professional interests have been identified as barriers to the development of IPE models (Evetts, 2005; DeMatteo and Reeves, 2013). The design and availability of learning spaces that can suitably support collaborative learning activities may also play a significant role in affording opportunities for IPE, or not.

Although IPE is understood to be important in anatomical education, the spatial support for this experience is often not incorporated in recommended actions (Thistlethwaite, 2015). Bainbridge and Wood (2013) reported that the following is required to promote IPE: first, a consideration of time, location, and space; second, time to reflect on the learning experiences and the interactions of health and human service providers at both individual and team levels; and third, opportunity to plan activities that promote interaction and collaboration amongst IPE participants, such as case-based learning and problem-based learning activities. These nested conditions incrementally specify learning spaces that are; first, suitable for learning; second, facilitate both individual presence and activity along with shared experiences and opportunities for reflection; and, third, allow for health professional educators to plan a range of activities (physical and/ or digital) that learners can engage in readily to expand opportunities for collaborative tasks and meaning making. Such affordances (Gibson, 1977) should encourage "collaborative success," which Kvan (2000) proposed is "achieved when something is accomplished in a group which could not be accomplished by an individual."

In keeping with Bainbridge and Wood's (2013) recommendation that further research should examine the characteristics of the practice environment, clinical settings, and organizational factors that can encourage students to participate in IPE, the focus of this descriptive article is on the role of space in the development of IPE models in health care, with particular focus on anatomical sciences education. 


\section{THE LEARNING SPACE AND LEARNING ENVIRONMENT}

For the purposes of this article it is important to discuss what is meant by the terms "learning space" and "learning environment." With growing academic interest in the connections between space and pedagogy (architecture and education) it is clear that the meanings of both terms are developing and are being transformed.

Although a learning space might once have been considered a physical entity defined by a certain geometry, researchers in the field have noted the shifting meaning of this term and the advance of more conceptual and socially constructed meanings (e.g., Boddington and Boys, 2011). Indeed, Boddington and Boys (2011) have suggested that the term "learning spaces" is being used to describe an emerging and complex field situated at the confluence of a number of disciplines, including education and design. Based-on research into school learning spaces undertaken using a sociomaterial methodological lens (Fenwick et al., 2011), Mulcahy et al. (2015) asked "What counts as a learning space?." They suggested that a narrow definition in physical terms is limiting and contended that: "A learning space is the product of heterogeneous relations: (1) a vision or a discursive dynamic such as 21st century learning, student-centered learning or personalized learning; (2) a design or a material dynamic such as a traditional classroom or a newly built open space or a mix of each; and (3) a shared structure or a social dynamic such as the organizational set up of the school" (Mulcahy et al., 2015).

Such a relationist way of thinking about learning spaces, informed by complexity theory, actor network theory (Fenwick et al., 2011), and concepts of spatiality-the social production of space-(McGregor, 2004; Massey, 2005), suggests that the physical aspects of learning spaces and the ways inhabitants understand and make use of spaces are created and sustained together through a mutually constitutive relationship. In this conceptualization, the ideas of those conceiving, designing, programming, and inhabiting a learning space are brought together to create a sociomaterial or sociospatial construct. This suggests that the discursive, material and social dynamic of a learning space is interconnected and that the meanings that people attribute to learning spaces are of equal importance to their physical layout and material construction (Cleveland, 2011). Such a perspective may be especially important in the context of understanding the usefulness, or pedagogical effectiveness, of a given learning space.

Similarly, the term "learning environment" has developed in recent years to encompass a more holistic meaning than was the case decades ago. Evidence of this can be seen in the interpretation of the term by one of the leading journals in the field, Learning Environments Research (Springer, 2015). This journal recognizes learning environments as "the social, physical, psychological, and pedagogical contexts in which learning occurs and which affect student achievement and attitudes" (Springer, 2015): a meaning that today may be somewhat narrow due to the increasingly widespread use of the same term in the context of digital, virtual, and smart learning environments (Hwang, 2014).

Although discourse regarding the material dynamic, or physical aspects, of learning environments in the health professions has been limited (Nordquist et al., 2013a), discussion about psychosocial learning environments has been prevalent in medicine for a more than 30 years. In 1984, Clarke et al. (1984) reported on a study about educational "climate," for which they used an assessment tool called the Medical School Learning Environment Survey. This tool, and their study, made no mention of the physical or material environment, but focused on students' medical breadth of interest, personal breadth of interest, emotional climate, flexibility, meaningful learning experience, organization, nurturance, and studentstudent interaction. Continued interest in psychosocial learning environments in medicine is highlighted by ongoing discourse about the use and refinement of this tool (see for example Stewart, 2006; and Rusticus et al., 2014).

So, just as the term "learning space" is being transformed, the term "learning environment" is similarly taking on a broader scope to include physical/environmental, pedagogical, social/interpersonal, intrapersonal, technological, and process-related components (Fisher and Abbasi, 2010).

\section{CONTEMPORARY DESIGN TRENDS FOR LEARNING SPACES IN HIGHER EDUCATION}

The literature concerning the role of architecture in higher education indicates that space can play an important role in supporting pedagogical activities and may influence students' and teachers' educational experiences (Jamieson et al., 2000; Carrick Institute, 2007; Radcliffe et al., 2008; Taylor and Enggass, 2008, Jamieson, 2009a; Bines and Jamieson, 2013, de la Harpe et al., 2014; Sutherland and Fischer, 2014). The physical environments in many higher education institutions are changing in response to contemporary ideas about learning and teaching, often centered on constructivist and other learner-centered pedagogies (Jamieson, 2009b). This trend is becoming increasingly evident as resource- and technologyrich facilities replace traditional learning spaces that were designed for didactic instruction (Radcliffe et al., 2008). The Scottish Funding Council (SFC, 2006) identified seven types of new learning spaces appearing on higher education campuses: group teaching/learning spaces; simulated environments; immersive environments; peer-to-peer and social learning environments; clusters; individual learning spaces; and external spaces. Collectively, these spaces (including integrated digital technologies) are challenging entrenched educational paradigms by providing opportunities for a broader range of learning and teaching modalities (JISC, 2006).

A report by the Carrick Institute for Learning and Teaching in Higher Education represented space variably as reflecting pedagogy, determining pedagogy, an agent of pedagogical change, and a vehicle for changing the education system (Carrick Institute, 2007). With a cautionary note, the report also suggested that the role of space needs to be kept in perspective, that desired pedagogies and space need to be aligned, and that the teacher will retain their teaching style unless there is some form of social intervention.

By contrast, the influence of education spaces on the pedagogical activities and educational experiences of health professional trainees and educators has not been well addressed in the literature, although interest in such matters is increasing (Nordquist et al., 2013b). Instead, studies of physical environments in hospitals have tended to focus on the influence of space on patient heath, with numerous studies linking evidence-based healthcare design to healthcare outcomes (Ulrich et al., 2008). 


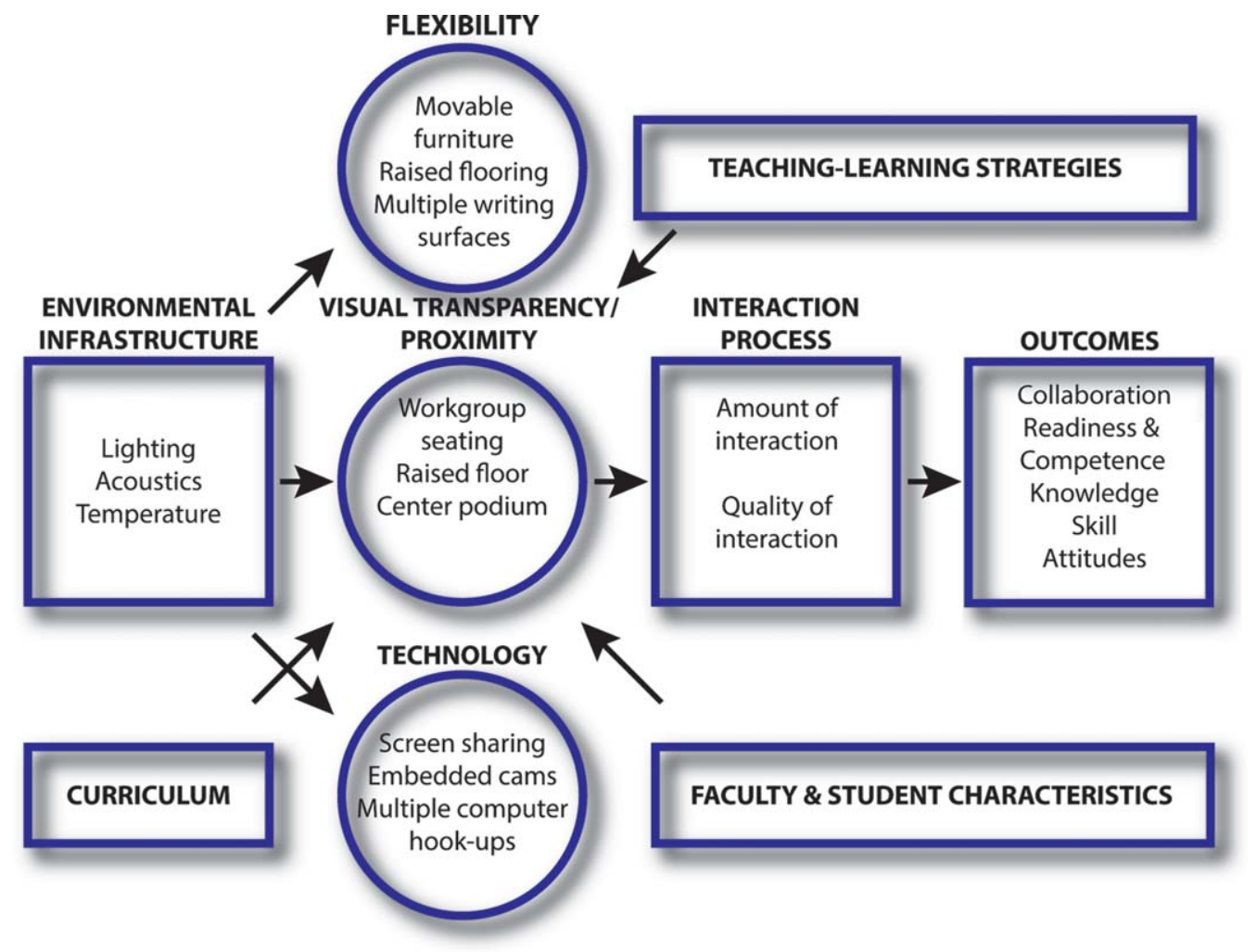

Figure 1.

Comprehensive collaboration-readiness model. Redrawn after Lamb and Shraiky (2013) with permission.

\section{TOWARD INTERPROFESSIONAL EDUCATION: THE ROLE OF SPACE}

The alignment of space to its purpose is readily acknowledged. For example, a well-designed emergency room can make the critical difference in facilitating effective delivery of care. The development of IPE curricula should also align with the learning environment (Nordquist et al., 2013a). Indeed, learning environments for IPE cannot be designed in isolation from the broader mechanisms of health professional education, be that on a university campus or in the community (Barr, 2013). Fernandes et al. (2015) provided an example in the context of delivering an IPE course in anatomy with laboratory dissection experience. They highlighted the need for "adequate physical space with access to cadaveric material, anatomy laboratory infrastructure, qualified staff to oversee the use of the laboratory, and funding."

The World Health Organization (WHO) qualified the need to align a variety of mechanisms in support of IPEincluding "environmental mechanisms." The WHO report entitled Framework for Action on Interprofessional Education \& Collaborative Practice, identified such mechanisms under two main themes: (1) educator mechanisms (e.g., academic staff training, champions, institutional support, managerial commitment, learning outcomes) and (2) curricular mechanisms (e.g., logistics and scheduling, program content, compulsory attendance, shared objectives, adult learning principles, contextual learning, assessment) (Hopkins, 2010). The report also suggested further mechanisms that shape how collaborative practice is introduced and executed: (1) institutional support mechanisms (e.g., governance models, structured protocols, shared operating resources, personnel policies, supportive management practices); (2) working culture mechanisms (e.g., communications strategies, conflict resolution policies, shared decision making processes); and (3) environmental mechanisms (e.g., built environment, facilities, space design) (Gilbert et al., 2010).

The role of environmental mechanisms in supporting medical education, and the promotion of IPE in particular, was the theme of the Future Learning Spaces conference held at Karolinska Institute, Stockholm, in 2012. This event led to a special issue of the Journal of Interprofessional Care (Informa, 2012), which explored a variety of matters related to how space impacts on learning in the health professions. Some prominent themes arising from the special issue included:

- The quality of design of physical learning spaces is now even more important, especially given the mobility and choice of location that users are afforded through their use of information and communication technologies (Laing and Bacevice, 2013).

- The development of new technological environments (digital and virtual) is providing opportunities to design more informal and multipurpose spaces, where formal and 


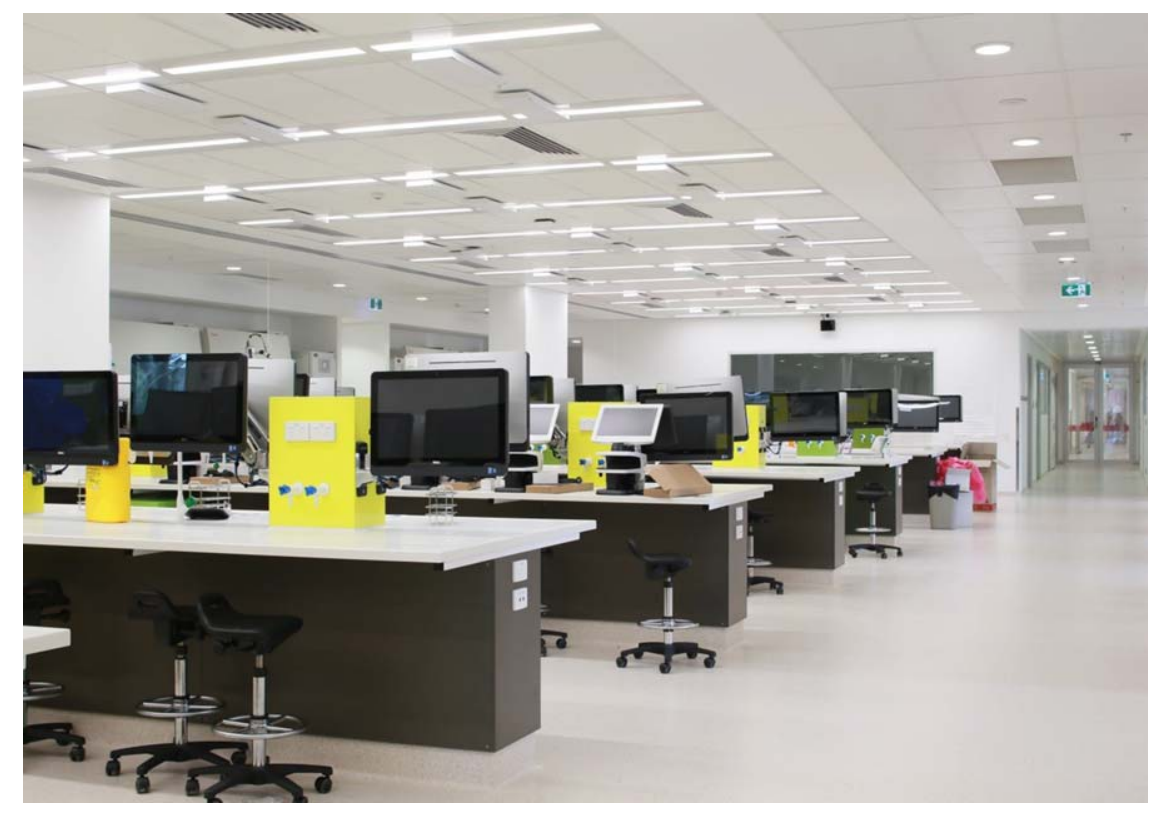

Figure 2.

X-Lab (wet teaching laboratory) at Charles Perkins Centre, University of Sydney in Sydney, New South Wales, Australia. Reprinted with permission from University of Sydney (2015).

specialized spaces would once have been favored (Laing and Bacevice, 2013).

- Formal learning and learning environments will remain an important component of health professional education curricula. Such practices and spaces will need to be integrated with new "liquid" and "nomadic" work and education practices (Bleakley, 2013).

Framed around the central theme of "competence in collaboration and teamwork," Lamb and Shraiky (2013) provided a theoretical model that integrates a number of the "mechanisms" the WHO suggested in support of IPE. Their Comprehensive Collaboration-Readiness Model (see Fig. 1) is intended to assist in the development of further testable models to "evaluate the relationship between physical design features and competency-based performance in teamwork and collaboration" (Lamb and Shraiky, 2013). The model clearly values the role of spatial design in the development of IPE and highlights the importance of generating learning and teaching opportunities sociomaterially through developing connections between design, teaching/learning, curriculum, and faculty and student characteristics.

\section{TWO EXEMPLAR FACILITIES THAT PROVIDE DIRECTION}

Two exemplar tertiary education facilities that integrate many of the ideas outlined above in support of IPE are discussed below: the Charles Perkins Centre at the University of Sydney in which basic science education is conducted in a research setting, and Victoria University's Interprofessional Clinic in Wyndham where a range of health care professions are educated together. Backed by well-conceived curriculum and pedagogical models, the architectures of these facilities embody the educational visions, methods, and practices they were designed to support.

\section{The Charles Perkins Centre}

The Charles Perkins Centre at the University of Sydney is a multiprofessional research and learning facility supporting several disciplines in working together in the fields of obesity, diabetes, and cardiovascular disease (University of Sydney, 2015). The center comprises wet and dry laboratories for teaching and learning, clinical research facilities, and other research support facilities. The concept of enabling collaborative discovery (van Joolingen, 2000) underpins the design. For example, the 240 student wet laboratory is designed for multiple classes concurrently (see Fig. 2). This setting allows students to hear and observe teachers undertaking procedures on personal screens located at each workplace, thus enabling collaboration within and across teams, whether they are colocated or not. The dry laboratory spaces provide for group work in pods, seminar spaces, and computer and microscopy laboratories. These are supported by technology that enables sharing of data and participation in activities (Lippincott, 2006). A student commons running through the building links the various learning spaces together and provides the social context for extended learning activities, interactivity, and collaboration (Jamieson, 2009b). In this setting, basic science teaching is conducted within a social and collaborative context of a multidisciplinary space, such as described by Bainbridge and Wood (2013).

\section{Victoria University's Interprofessional Clinic}

Victoria University's Interprofessional Clinic in Wyndham brings together students from several disciplines, including 


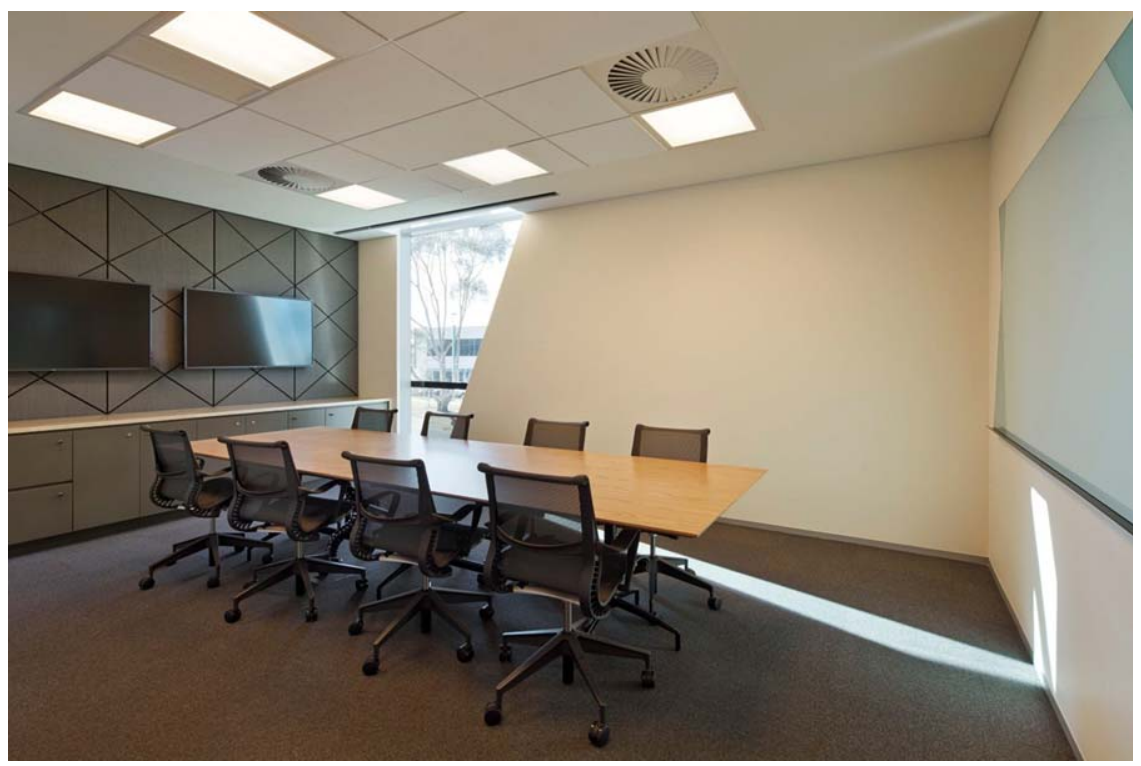

\section{Figure 3.}

Team room at the Interprofessional Clinic in Wyndham, Victoria University in Melbourne, Victoria, Australia (IPEP, 2015). Architecture: Woods Bagot. Photograph: Peter Bennetts, reproduced with permission.

nursing, midwifery, paramedicine, psychology, dietetics, dermal science, exercise physiology, osteopathy, nutrition, and social work to experience interprofessional clinical practice under the supervision of teachers and registered health practitioners (Victoria University, 2014). To support both undergraduate and graduate education, spaces include inter-

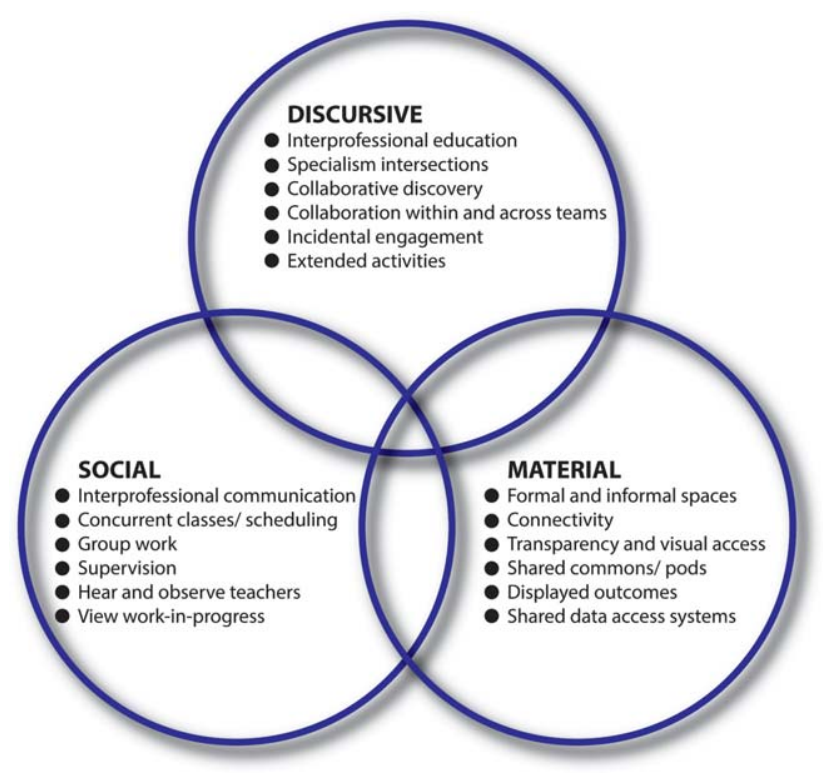

Figure 4.

Learning space variables in support of interprofessional education: a sociomaterial perspective. professional pods, a teaching kitchen for food preparation, and an active living laboratory where clients are assisted in rehabilitation to maximize quality of movement. To facilitate the interprofessional communication experience, these spaces are supported by video-link technology and shared data access systems throughout the facility. The interprofessional pods are provided with a client assessment/debrief room and a team room (see Fig. 3) that carters for eight students from different disciplines working together under supervision. The facility supports Victoria University's IPE model, in which students are introduced to interprofessional practice early in the program, following a model of Expose, Immerse, and Experience (IPEP, 2015). This staged program supports students to develop an understanding of interprofessional practice theory (Expose), provides them with opportunities to participate in simulated interprofessional practice (Immerse), and engages them in work with a range of professions in a functioning clinical care environment under the supervision of qualified staff (Experience).

As can be identified in the descriptions of the two exemplars above, a number of discursive, material and social variables must interact to produce learning spaces in support of IPE. Figure 4 provides a model of some key variables and suggests their interaction.

The thorough articulation of the discursive narrative, or vision, which drives the development of an IPE model is critical when designing new learning spaces. Developing detailed understandings of the educational philosophy, curriculum, and the methods of teaching and learning that will be favored is pivotal to generating a supportive design response. Importantly, the narrative must not stop with the architectural design team; it should be carried beyond and shared with those participating in IPE programs-most importantly the teachers and students. Communicating the vision to those responsible for generating the social dynamic is important 
work, as the "becoming" of new learning spaces occurs not when they are built, but when the inhabitants develop (socially) the methods and practices of teaching and learning that will become habituated. Ideally, these practices will take advantage of the affordances embodied in the architecture, but design does not determine practice and people often need support to recognize what opportunities exist for different forms of practice in new facilities, such as required when developing new IPE models.

\section{LEARNING SPACE DESIGN FOR INTERPROFESSIONAL EDUCATION IN THE ANATOMICAL SCIENCES}

Although the best methods for teaching anatomy are still being debated (Kerby et al., 2011), recent studies have indicated that hybrid teaching models that combine didactic instruction with computer-aided learning, problem-based learning, clinical correlational lectures, peer teaching, and the use of models, imaging, and surface anatomy provide a more engaging learning experience for students and improve overall performance in anatomy examinations, as well as later performance in radiology, surgery, and neurology classes (Johnson et al., 2012).

To design new anatomy facilities able to accommodate educational innovations, Trelease (2006) concluded that although architects are the key agents in producing spaces for flexible and innovative anatomical education, a process of "successive approximation" involving cooperation between anatomists and architects is the key to achieving effective design outcomes. Trelease also pointed to the fact that "there are many more types of anatomy laboratories in use than the very specialized medical school facilities ... [including] those in community, private, and liberal arts colleges, osteopathic, chiropractic, and physical therapy schools." He concluded that web-based multimedia and modern computer-reliant teaching laboratories might best serve the needs of many organizations teaching the anatomical sciences, "especially those less likely to depend on large-scale student dissection exercises and associated donated body programs" (Trelease, 2006). It was also Trelease's contention that large medical schools should continue using and planning dissection laboratories, especially to support clinical in-service and residential training for surgery.

When discussing the history of the anatomical theater and the development of new multimodal environments for anatomy education, Macchi et al. (2014) proclaimed that "the anatomical theater has become the flagship of a renewal of the medical curriculum, bringing with it a systemic and methodological revolution in medical education." In line with this renewal, they identified a pedagogical shift from the historically based practice of affording students the opportunity to "see and watch" anatomical dissections, to engaging them to "see and do" as active participants in anatomy classes. They suggested that active student participation in learning removed barriers to communication between students and teachers and encouraged individual engagement with the subject matter.

Like others (Trelease, 2006; Goldman, 2010; Wessels and Rennie, 2013; Wessels et al., 2015), Macchi and colleagues emphasized the need for the design of new anatomy education facilities to respond to changing curricula and pedagogies (Macchi et al., 2014). They identified the need to provide learning environments that can cater to traditional methods (lectures, textbooks, and atlases), newer educational technologies (computer aided learning and multimedia), and practical laboratory sessions (dissections, plastic models, plastinated specimens, and radiological imaging). Additionally, they suggested that new mobile technologies should be integrated into the learning environment to aid learner engagement, help achieve educational objectives, and support the effectiveness and efficiency of dissection (Macchi et al., 2014).

In a short report, Fisher (2012) suggested a framework for the construction of flexible learning centers, or learning hubs, that can afford students the opportunity to work across a range of learning modalities, either independently or in teams, as members of a learning community. He proposed a spatial organizing tool based on three space typologies: Mode 1 (teacher-centered), Mode 2 (student-centered), and Mode 3 (informal or social) and suggested that all three types should be co-located to allow students to move between them as required to fulfill their learning needs.

Marrying Fisher's (2012) ideas about learning hubs and space typologies with Johnson et al.'s (2012) ideas about hybrid-teaching models and Macchi et al.'s (2014) visions for a variety of learning environments to suit different teaching methods, points toward the need to co-locate a variety of physical settings in support of IPE in the anatomical sciences. Affording varying degrees of visual transparency and interconnectivity, depending on the principle purpose of each setting, such spaces might include specialized wet and dry laboratories, as well as a variety of nonspecialized spaces that can adapt to different forms of use and different forms of practice. In total, such learning hubs would ideally support the variety of teaching methods outlined by Johnson et al. (2012), i.e., didactic instruction, computer-aided learning, problem-based learning, clinical correlational lectures, peer teaching, and the use of models, imaging, and surface anatomy. They would also support dissection activities in instances where course requirements necessitated it. Such learning hubs could adjoin other educational facilities to generate spatial efficiencies, especially with respect to the Mode 3 (informal or social) settings. These could readily be shared with other departments, thus encouraging cross-disciplinary collaboration. Aspects of this multimodal approach to learning space design can be seen in the design of a new facility for teaching and research in clinical anatomy in the United Kingdom, as described by Greene (2009).

\section{EVALUATION}

Kitto et al. (2013) noted the medical fields' growing understanding of the role of space in professional education and set out a research agenda concerning the connections between space and interprofessional learning. These authors articulated four dimensions of such research: (1) to explore how space, place, and learning intersect; (2) to ensure that the work is across disciplines; (3) to develop common methodologies; and (4) to expand the work to illuminate the lived experiences of those engaged in such activities (Kitto et al., 2013).

It seems logical that a significant portion of such research would fall into the category of evaluation. Feedback about the complex interactions between space and learning experiences, including the outcomes of such experiences, is required to inform decisions about how best to design and develop 
learning spaces for IPE programs. As Lamb and Shraiky (2013) suggested: "Many universities in the United States are investing in classrooms and campuses designed to increase collaboration and teamwork among the health professions. To date, we know little about whether these learning spaces are having the intended impact on student performance."

Kvan (2013) argued that "we cannot undertake control trials, randomized or not, to tease out relevant factors in the design of buildings." He suggested that the evidence must include qualitative dimensions of the learning experience (Kvan, 2013). Such an approach is aligned with renewed interest in evaluation at the intersection of the physical and the social and a return to the origins of post occupancy evaluation in environmental psychology (Cleveland and Fisher, 2014). It is also aligned with Preiser and Nasar's (2008) view that a new perspective on building evaluation is currently being developed that favors the opinions of the user.

To achieve better alignment between learning activities, experiences, and space, Kvan (2013) suggested an evaluation framework based on Kirkpatrick's (1996) model for the evaluation of training programs. He proposed a four-level model for the effective evaluation of interprofessional learning environments based on the following levels and corresponding guiding questions: (1) Reaction-Do the learners like the learning environment which they are using?; (2) LearningDo the learning environments facilitate student engagement in the learning or does it frustrate their efforts?; (3) Behavior-Do the learning environments extend and enhance learning through active participation, allowing the learning to be translated into application or behaviors? Do the collective learning environments available to students promote ongoing learning so that it can translate out of the classroom into the surrounding spaces?; (4) Results-Do the learning environments contribute to improved learning experiences and outcomes for the institution/school? (Kvan, 2013).

Preiser and Nasar (2008) suggested that feedback of this type can (1) help localized users get the most out of the physical environments they already have and (2) inform education systems about the types of spaces and spatial arrangements that are best meeting the educational objectives of the institutions in a particular system.

\section{DISCUSSION}

The authors identified the growing support for IPE in the health professions toward preparing students for "effective teamwork and collaborative decision making in clinical practice" (Lamb and Shraiky, 2013). Furthermore, the article discussed the growing recognition of the environmental mechanisms that can support IPE and the need to make available educational facilities that are designed to support the types of learning activities that are understood to encourage the development of the knowledge, skills, values, and belief systems that are associated with an interprofessional approach to patient-centered health care, that is, the sharing of knowledge and the inclusion of other bodies of knowledge through interactivity and collaboration.

The need to recognize the heterogeneous nature of "learning spaces" was discussed, and it was noted that learning spaces need to be developed not only materially, but socially, in keeping with the discursive narrative driving the development of IPE models.

Two exemplars highlighted how different approaches to interprofessionalism in basic and health sciences have been embodied in recently constructed educational facilities. These facilities represent rigorous attempts to break down previously siloed methods of professional education delivery, with a desire to promote intersections between specialisms through the design of new learning spaces. They show how learning spaces are being designed and developed for a range of learning purposes across different phases of the tertiary education continuum and highlight that IPE models can be applied in premedical science education. Discussion of the Charles Perkins Centre, in particular, illustrated how an advanced research facility can be configured to include undergraduate education experiences that support both specialist training and collaborative team engagement. An early introduction to these concepts at undergraduate level can prepare students to become committed interprofessional practitioners and for later IPE development. Leveraging this discussion, the spatial implications for IPE in the anatomical sciences were explored amidst the context of changing curricula and pedagogies. It was suggested that the design of multimodal learning hubs, featuring Mode 1 (teacher-centered), Mode 2 (student-centered), and Mode 3 (informal or social) space typologies, should be explored to encourage the development of hybrid learning models (Johnson et al., 2012) and cross-disciplinary collaborative practice.

\section{CONCLUSIONS}

To achieve successful and sustainable IPE models, learning spaces should be designed and developed (socially) with the express intention of supporting transparency, interactivity, and collaboration between the health professions. It is also recognized that new facilities must be able to adapt to changing needs. The concepts driving IPE are evolving, and so the spaces accommodating emerging IPE models must also allow for change. The value of evaluating new and existing learning spaces with an emphasis on the user perspective/experience should be recognized for the dual purpose of helping localized users get the most out of the physical environments they already have and informing education systems about what types of spaces and spatial arrangements are best meeting current and evolving educational objectives. It seems highly likely that developing and evaluating new IPE models in new learning spaces will contribute to the development of more effective educational programs in the anatomical sciences, as well as in other disciplines, across all phases of the medical educational continuum.

\section{ACKNOWLEDGMENTS}

The authors thank the Learning Environments Applied Research Network (LEaRN) at the University of Melbourne for supporting the writing of this article. In particular, the authors thank Dr. Sue Wilks and Associate Professor Clare Newton for their research work on a related project that informed their thinking. The authors are indebted to the Faculty of Architecture, Building, and Planning, Melbourne Graduate School of Education, and the Faculty of Medicine, Dentistry, and Health Sciences, and LEaRN industry and education partners, Hayball, Catholic Education Office Melbourne, Anglican Church Grammar School, Indec-ARUP, Keepad Interactive, and the Australian School of Mathematics and Science for their support.

\section{NOTES ON CONTRIBUTORS}

BENJAMIN CLEVELAND, Ph.D., is a research fellow with the Learning Environments Applied Research Network 
(LEaRN) at the University of Melbourne, Melbourne, Australia. He oversees the LEaRN research program, which seeks to bring academic rigor to the contemporary discussion about how best to support educational practice with architecture and digital technology. His research interest is in aligning educational practice and space.

THOMAS KVAN, Ph.D., is Dean of the Faulty of Architecture, Building, and Planning, Assistant Vice Chancellor (Campus Development) and Director of the Learning Environments Applied Research Network at the University of Melbourne, Melbourne, Australia. He is internationally recognized for his work in the management of design practice and development of digital applications in design.

\section{LITERATURE CITED}

Arky RA. 2006. Shattuck lecture. The family business-To educate. N Engl J Med 354:1922-1926.

Bainbridge L, Wood VI. 2013. The power of prepositions: A taxonomy for interprofessional education. J Interprof Care 27:131-136.

Barr H. 1996. Ends and means in interprofessional education: Towards a typology. Educ Health Change Learn Pract 9:341-352.

Barr H. 2013. Enigma variations: Unravelling interprofessional education in time and place. J Interprof Care 27:S9-S13.

Bines JE, Jamieson P. 2013. Designing new collaborative learning spaces in clinical environments: Experiences from a children's hospital in Australia. J Interprof Care 27:S63-S68.

Bleakley A. 2013. The dislocation of medical dominance: Making space for interprofessional care. J Interprof Care 27:S24-S30.

Bleakley A, Bligh J, Browne J. 2011. Medical Education for the Future: Identity, Power and Location. 1st Ed. London, UK: Springer Science+Business Media B.V. 291 p.

Boddington A, Boys J. 2011. Re-shaping learning-An introduction. In: Boddington A, Boys J (Editors). Re-Shaping Learning: A Critical Reader. The Future of Learning Spaces in Post-Compulsory Education. 1st Ed. Rotterdam, The Netherlands: Sense Publishers. p xi-xxii.

CAIPE. 2002 Centre for the Advancement of Interprofessional Education. Defining IPE. Centre for the Advancement of Interprofessional Education, Fareham, UK. URL: http://caipe.org.uk/about-us/defining-ipe/ [accessed 30 March 2015].

Carrick Institute. 2007. Draft Report: Places and Spaces for Learning Seminars. September 2007. 1st Ed. Strawberry Hills, NSW, Australia: Carrick Institute for Learning and Teaching in Higher Education. 77 p. URL: https:// eprints.usq.edu.au/4070/1/Huijser_Elson-Green_Reid_Walta_Challis_Harris_ McCafferty.pdf [accessed 8 March 2015].

Clarke RM, Feletti GI, Engel CE. 1984. Student perceptions of the learning environment in a new medical school. Med Educ 18:321-325.

Cleveland BW. 2011. Engaging spaces: Innovative learning environments, pedagogies and student engagement in the middle years of school. The University of Melbourne: Melbourne, Vic, Australia. Doctorate of Philosophy Dissertation. $301 \mathrm{p}$.

Cleveland B, Fisher K. 2014. The evaluation of physical learning environments: A critical review of the literature. Learn Environ Res 17:1-28.

Cooke M, Irby DM, O’Brian BC, Shulman LS. 2010. Educating Physicians: A Call for Reform of Medical School and Residency. 1st Ed. San Francisco, CA: Jossey-Bass. 320 p.

Cooke M, Irby DM, Sullivan W, Ludmerer KM. 2006. American medical education 100 years after the Flexner report. N Engl J Med 355:1339-1344.

de la Harpe B, Fraser K, Mason T, Hurford J. 2014. Transforming Teaching Practice Through Professional Learning for Next Generation Learning Spaces. Learning and Teaching Investment Fund Final Report. 1st Ed. Melbourne, Victoria, Australia: Office of Pro-Vice Chancellor, RMIT University. 32 p. URL: http://mams.rmit.edu.au/750b2f9b9j4yz.pdf [accessed 8 March 2015].

DeMatteo DJ, Reeves S. 2013. Introducing first year students to interprofessionalism: Exploring professional identity in the "enterprise culture": A Foucauldian analysis. J Interprof Care 27:27-33.

Dornan T, Mann K, Scherpbier A, Spencer J (Editors). 2011. Medical Education: Theory and Practice. 1st Ed. Edinburgh, UK: Churchill Livingstone Elsevier Ltd. 396 p.

Evetts J. 2005. The management of professionalism: A contemporary paradox. In: Proceedings of the Changing Teacher Roles, Identities and Professionalism Seminar Series; London, UK, 2005 Oct 19. Kings College, London, UK. URL: http://www.tlrp.org/dspace/retrieve/1858/paper-evetts.pdf [accessed 8 March 2015].

Fenwick T, Edwards R, Sawchuk P. 2011. Emerging Approaches to Educational Research: Tracing the Sociomaterial. 1st Ed. Abingdon, Oxon, UK: Routledge. 232 p.
Fernandes AR, Palombella A, Salfi J, Wainman B. 2015. Dissecting through barriers: A mixed-methods study on the effect of interprofessional education in a dissection course with health care professional students. Anat Sci Educ 8: 305-316.

Fisher K. 2012. The New Learning Environment: Hybrid Designs for Hybrid Learning. 1st Ed. Melbourne, Victoria, Australia: Woods Bagot. 8 p. URL: https://isredevelopment.files.wordpress.com/2012/01/public2-the-new-learningenvironment.pdf [accessed 8 March 2015].

Fisher K, Abbasi N. 2010. LEaRN Working Paper 1. 1st Ed. Melbourne, Victoria, Australia: Learning Environments Applied Research Network, University of Melbourne. 87 p.

Flexner A. 1910. Medical Education in the United States and Canada. A Report to the Carnegie Foundation for the Advancement of Teaching. Carnegie Bulletin 4. 1st Ed. Boston, MA: D.B. Updike, The Merrymount Press. 336 p.

Freeth DS, Hammick M, Koppel I, Barr H. 2005. Effective Interprofessional Education: Development, Delivery, and Evaluation. 1st Ed. Oxford, UK: Blackwell Publishing. 208 p.

Gibson JJ. 1977. The theory of affordances. In: Shaw R, Bransford J (Editors). Perceiving, Acting, and Knowing: Toward an Ecological Psychology. 1st Ed. New Hillsdale, NJ: Lawrence Erlbaum. p 67-82.

Gilbert JH, Yan J, Hoffman SJ. 2010. A WHO report: Framework for action on interprofessional education and collaborative practice. J Allied Health 39: S196-S197.

Goldman E. 2010. Building a low-cost gross anatomy laboratory: A big step for a small university. Anat Sci Educ 3:195-201.

Greene JR. 2009. Design and development of a new facility for teaching and research in clinical anatomy. Anat Sci Educ 2:34-40.

Hamilton SS, Yuan BJ, Lachman N, Hellyer NJ, Krause DA, Hollman JH, Youdas JW, Pawlina W. 2008. Interprofessional education in gross anatomy: Experience with first-year medical and physical therapy students at Mayo Clinic. Anat Sci Educ 1:258-263.

Herrmann G, Woermann U, Schlegal C. 2015. Interprofessional education in anatomy: Learning together in medical and nursing training. Anat Sci Educ 8: 324-330.

Hopkins D (Editor). 2010. Framework for Action on Interprofessional Education \& Collaborative Practice. 1st Ed. Geneva, Switzerland: Health Professions Networks Nursing and Midwifery Human Resources for Health, World Health Organization Press. 64 p. URL: http://whqlibdoc.who.int/hq/2010/WHO_ HRH_HPN_10.3_eng.pdf [accessed 8 March 2015].

Hwang GJ. 2014. Definition, framework and research issues of smart learning environments-A context-aware ubiquitous learning perspective. Smart Learn Environ 1:14.

Informa. 2012. Journal of Interprofessional Care. Volume 27, Number S2 (September 2013). Future Learning Spaces. London, UK: Informa Healthcare. URL: http://informahealthcare.com/toc/jic/27/S2 [accessed 8 March 2015].

IPEP. 2015. Interprofessional Education Program. Melbourne, Victoria, Australia: Interprofessional Clinic in Wyndham, Victoria University. URL: http:// www.vu.edu.au/interprofessional-education-program-ipep/interprofessionalclinic-in-wyndham [accessed 8 March 2015].

Jamieson P. 2009a. Developing the university campus as a place of learning. In: Newton C, Fisher K (Editors). Take 8: Learning Places: The Transformation of Educational Spaces for the 21st Century. 1st Ed. Manuka, ACT, Australia: Australian Institute of Architects. p 68-77.

Jamieson P. 2009b. The serious matter of informal learning. Plann High Educ 37:18-25.

Jamieson P, Fisher K, Gilding T, Taylor PG, Trevitt ACF. 2000. Place and space in the design of new learning environments. High Educ Res Dev 19:221-237.

JISC. 2006. Joint Information Systems Committee. Designing Spaces for Effective Learning: A Guide to 21st Century Learning Space Design. 1st Ed. Bristol, UK: Joint Information Systems Committee Development Group. 36 p. URL: http:// www.webarchive.org.uk/wayback/archive/20140616001949/ http://www.jisc.ac.uk/ media/documents/publications/learningspaces.pdf [accessed 8 March 2015].

Johnson EO, Charchanti AV, Troupis TG. 2012. Modernization of an anatomy class: From conceptualization to implementation. A case for integrated multimodal-multidisciplinary teaching. Anat Sci Educ 5:354-366.

Kerby J, Shukur ZN, Shalhoub J. 2011. The relationships between learning outcomes and methods of teaching anatomy as perceived by medical students. Clin Anat 24:489-497.

Kirch DG, Ast C. 2015. Interprofessionalism: Educating to meet patient needs. Anat Sci Educ 8:296-298.

Kirkpatrick D. 1996. Revisiting Kirkpatrick's four-level model. Train Dev 50: 54-59.

Kitto S, Nordquist J, Peller J, Grant R, Reeves S. 2013. The disconnections between space, place and learning in interprofessional education: An overview of key issues. J Interprof Care 27:S5-S8.

Kvan T. 2000. Collaborative design: What is it? Autom Construct 9:409-415.

Kvan T. 2013. Evaluating learning environments for interprofessional care. J Interprof Care 27:S31-S36.

Laing A, Bacevice PA. 2013. Using design to drive organizational performance and innovation in the corporate workplace: Implications for interprofessional environments. J Interprof Care 27:S37-S45. 
Lamb G, Shraiky J. 2013. Designing for competence: Spaces that enhance collaboration readiness in healthcare. J Interprof Care 27:S14-S23.

Lippincott JK. 2006. Linking the information commons to learning. In: Oblinger DG (Editor). Learning Spaces. 1st Ed. Boulder, CO: Educause. p 7.1-7.18.

Louie AK, Roberts LW, Coverdale J. 2007. The enculturation of medical students and residents. Acad Psychiatry 31:253-257.

Macchi V, Porzionato A, Stecco C, De Caro R. 2014. Evolution of the anatomical theatre in Padova. Anat Sci Educ 7:487-493.

Massey DB. 2005. For Space. 1st Ed. London, UK: Sage Publications Ltd. 232 p.

McColl G. 2014. The future of medical education. In: Proceedings of the Symposium on Talking Spaces 6: Medical Stream Snapshot Presentations; Melbourne, Australia; 2014 Aug 6-7. Snapshot A. The University of Melbourne, Melbourne, Vic, Australia. URL: http://e21le.com/publication_type/video/ [accessed 8 March 2015].

McGregor J. 2004. Spatiality and the place of the material in schools. Pedagog Cult Soc 12:347-372.

McNair R, Stone N, Sims J, Curtis C. 2005. Australian evidence for interprofessional education contributing to effective teamwork preparation and interest in rural practice. J Interprof Care 19:579-594.

Mulcahy D, Cleveland B, Aberton H. 2015. Learning spaces and pedagogic change: Envisioned, enacted and experienced. Pedagog Cult Soc (in press, doi: 10.1080/14681366.2015.1055128).

Nordquist J, Kitto S, Reeves S. 2013a. "Living museums": Is it time to reconsider the learning landscape for professional and interprofessional education? J Interprof Care 27:S2-S4.

Nordquist J, Sundberg K, Kitto S, Ygge J, Reeves S. 2013b. Future learning environments: The advent of a "spatial turn"? J Interprof Care 27:S77-S81.

Preiser WFE, Nasar JL. 2008. Assessing building performance: Its evolution from post-occupancy evaluation. Int J Architect Res 2:84-99.

Radcliffe D, Wilson H, Powell D, Tibbetts B. 2008. Designing Next Generation Places of Learning: Collaboration at the Pedagogy-Space-Technology Nexus. ALTC Priority Project \#627. 1st Ed. Strawberry Hills, NSW, Australia: Australian Learning and Teaching Council. 20 p.

Reeves S, Hean S. 2013. Why we need theory to help us better understand the nature of interprofessional education, practice and care. J Interprof Care 27:1-3. Rusticus S, Worthington A, Wilson D, Joughin K. 2014. The medical school learning environment survey: An examination of its factor structure and relationship to student performance and satisfaction. Learn Environ Res 17:423435 .
SFC. 2006. Scottish Funding Council. Spaces for Learning: A Review of Learning Spaces in Further and Higher Education. 1st Ed. Edinburgh, UK: AMA Alexi Marmot Associates. 46 p. URL: http://aleximarmot.com/userfiles/file/ Spaces\%20for\%20learning.pdf [accessed 8 March 2015].

Sutherland R, Fischer F. 2014. Future learning spaces: Design, collaboration, knowledge, assessment, teachers, technology and the radical past. Tech Pedagog Educ 23:1-5.

Springer. 2015. Learning Environments Research. Description. Volume 18 Springer International Publishing AG, Cham, Switzerland. URL: http://link. springer.com/journal/10984 [accessed 8 March 2015].

Stewart TJ. 2006. Learning environments in medical education. Med Teach 28:387-389.

Taylor A, Enggass K. 2008. Linking Architecture and Education: Sustainable Design for Learning Environments. 1st Ed. Albuquerque, NM: University of New Mexico Press. 471 p.

Thistlethwaite JE. 2015. Interprofessional education and the basic sciences: Rationale and outcomes. Anat Sci Educ 8:299-304.

Trelease RB. 2006. Anatomy meets architecture: Designing new laboratories for new anatomists. Anat Rec 289B:241-251.

Ulrich RS, Zimring C, Zhu XM, DuBose J, Seo HB, Choi YS, Quan X, Joseph A. 2008. A review of the research literature on evidence-based healthcare design. HERD 1:61-125.

University of Sydney. 2015. The University of Sydney, Charles Perkins Centre. Teaching and Learning Spaces. Sydney, NSW, Australia: The University of Sydney. URL: http://sydney.edu.au/perkins/research-education-hub/teaching-learning-spaces.shtml [accessed 8 March 2015].

van Joolingen WR. 2000. Designing for collaborative discovery learning. Lect Notes Comput Sci 1839:202-211.

Victoria University. 2014. IPEPVU: Interprofessional education program. IPEP Newsletter, August 2014. Melbourne, Victoria, Australia: Victoria University. 4 p. URL: www.vu.edu.au/sites/default/files/ipep/pdfs/IPEP-Newsletter-Winter2014-web.pdf [accessed 20 March 2015].

Wessels Q, Rennie T. 2013. Reflecting on interprofessional education in the design of space and place: Lessons from Namibia. J Interprof Care 27:S69S71.

Wessels Q, Vorster W, Jacobson C. 2015. Designing gross anatomy laboratory to meet the needs of today's learner. In: Chan LK, Pawlina W (Editors). Teach ing Anatomy: A Practical Guide. 1st Ed. New York, NY: Springer International Publishing. p 185-194. 